\title{
DESIGN AND IMPLEMENTATION OF A MICROCONTROLLER BASED DUAL AXIS SOLAR RADIATION TRACKER
}

\author{
J. E. Okhaifoh ${ }^{1}$ and D.E. Okene ${ }^{2, *}$ \\ 1, 2, Dept. of Elect \& Electronics Engr., Fed. Univ. of Petroleum Resources, EFFurun, Delta State, NiGERIA \\ E-mail addresses:1 jokhaifoh@yahoo.com, 2ese4all2002@yahoo.com
}

\begin{abstract}
In this paper, an efficient microcontroller-based dual axis solar radiation tracker which can be used to align a single photovoltaic (PV) module or an array of module with the sun is implemented. It employs a dual axis tracking system in its control circuitry as against the popularly employed programmable logic array. Performance analysis of the dual axis solar tracker was conducted in a test bed in Department of Electrical and Electronics Engineering, Federal University of Petroleum Resources, Effurun, Nigeria and results showed that the power output of the photovoltaic (PV) system had $58.4 \%$ improvement when compared with the traditional method of fixed solar panel. The dual axis system also has the benefit of reduction in the number of solar panels to be deployed because of the gains in power output and efficiency.
\end{abstract}

Keywords: Solar Panel, Light Dependent Resistors, Dual Axis Tracker, Micro Controller, Photovoltaic Cells, Servo Motors

\section{INTRODUCTION}

For Nigeria to be able to grow its economy, and attain its Millennium Development Goals (MDGs), stable electric power supply is inevitable. Recently, a lot of investments have been made in the nation's power sector with very little or no improvement in power supply. The focus of these investments has been on the traditional methods of power generation such as Thermal, Hydro, Coal and Steam. However, there is a global shift towards green energy. The reasons are primarily because the traditional sources of power generation are depleting and this same traditional sources are also largely responsible for global warming [1].

Energy demands in Nigeria are growing at a tremendous rate. According to [2], University of Maiduguri, Nigeria for instance spends ten million naira $(\$ 31,152.6)$ weekly to run its diesel generators that provide electricity to the campus. This would in no doubt increase the University's running cost. This situation to, a large extent, is the general reflection of the power situation here in Nigeria. If urgent steps are not taken to explore renewable energy sources in addition to the fossil fuels that are been used for power generation, a major power crisis will be inevitable Ontario in Canada for instance, has shut down all its coal-fired generating stations and replaced them with wind turbine generating stations. Renewable energy now accounts for $35 \%$ of total power generated [1].

Solar energy is readily available in most parts of tropical Africa with Nigeria receiving yearly average of $5.61 \mathrm{KWh} / \mathrm{m}^{2}$ among others [2,3]. In the tropics, the sun appears to follow a path that is directly overhead. However, for locations north of the tropics, the sun never reaches a position that is directly overhead; instead it follows a path across the southern path of the sky [4]. In addition to this, the movement of the sun from east to west has a great effect on the radiation that can be gotten from the sun.

Also, research conducted by [5], showed that the current obtained from solar cells is greatly influenced by the angle at which incident rays strike the cell surface. Using a stationary light source and adjusting the angle at which the light rays strike the cell, a plot of current delivered vs. angle .of incidence was created as shown by Figure 1

From Figure 1, it can be stated that, to maintain maximum power output from a solar array, the angle of incidence must be held at zero degrees. Hence, the array must constantly face the sun. This requires a 
tracking system that can continuously align the array into the desired position.

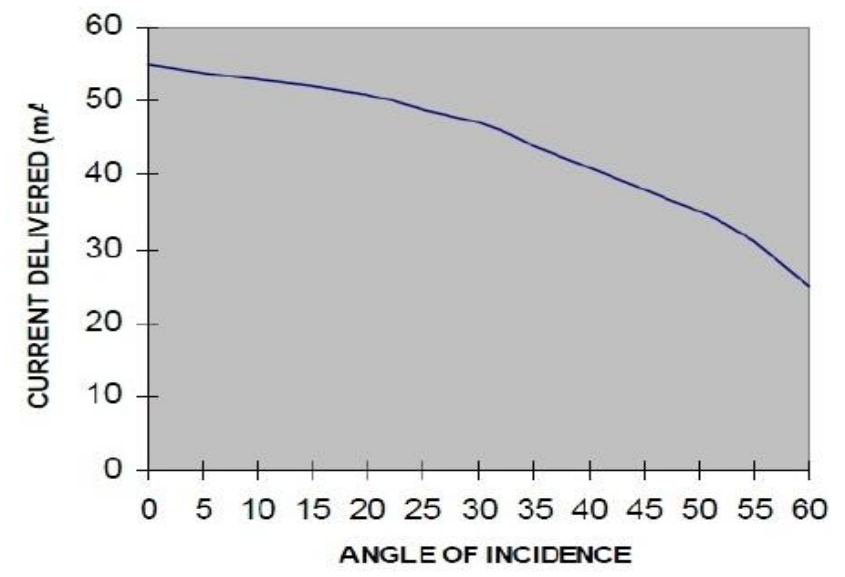

Figure 1:Graph of Current Delivered vs Angle of Incidence [5]

A systematic solution to these problems of getting maximum radiation is by developing a tracking system that at every point in time adjusts itself to face the sun in the direction of highest radiation. A Solar tracker is a sensory device built with a solar panel that tracks the motion of the sun across the sky and moves the solar panel along, ensuring that maximum amount of sunlight strikes the panel throughout the day [6].Several energy companies and research institutions have been performing solar tracking for improving the efficiency of solar energy production. In commercial terms, there are two types of solar tracking systems- single axis and dual axis. The paper [6] opined that dual axis solar trackers are better than single axis solar trackers. The reason is that the earth has two types of motion, daily motion and annual motion. Therefore, using a single axis tracker would reduce the efficiency of the solar panel. From the foregoing, [6] developed a dual axis tracking system which comprises light dependent resistors (LDRs) for sensing light intensity, Op-amps serving as comparators, a microcontroller which generates the control signals for moving the motors in the right direction and two $12 \mathrm{v}$ stepper motors for rotating the solar panel in different axes. The average power gain of the tracking system when compared with the static one was $52.78 \%$.

It was observed by [7] that the power density on a solar panel depends on the tilt angle. And that for energy yield to be optimized, there was need for the manual adjustment of the tilt angle on a monthly basis. This method is not intelligent or self-driven since human intervention is involved. In [8], only one axis was tracked and power supply to the system was from mains. The power gain was $5.77 \%$ when compared to the fixed panel. This energy gain is considerably low compared to other tracking system discussed earlier. Also, reliance on an erratic mains supply could defeat the very aim of this alternative power supply system.

Most tracking systems use microcontrollers for their control circuitry, however, in [9] a programmable logic control (PLC) device was used. The performance of the PLC dual axis solar radiation tracker was not nonetheless better than that of micro controller controlled systems. The power gain according to [9] was $25 \%$ when compared to fixed solar panels. So the PLC controlled solar radiation tracker does not really offer more benefits than the micro controlled type according to results from [9].

In all, the cost of these systems discussed above is however still very prohibitively high for the average consumer or for a small-scale application. Hence, the aim of this work is to design and implement a low-cost microcontroller-based dual axis solar radiation tracker which has both horizontal and vertical axle that can track the sun's apparent motion. it can be programmed for location flexibility and used for small scale applications especially in academic institutions.

The major components that form the backbone this design are, the light detecting resistor, Atmega328p Microcontroller, servo motor and a 9V DC battery source.

The micro controller used was AVR ATMEGA328P PU. It is a 28pin 8bit microcontroller with a $32 \mathrm{~KB}$ flash memory. It also possesses an analogue to digital converter which plays a key role in the overall design of the system.

\section{METHODOLOGY AND SYSTEM DESIGN}

The project was designed and implemented using the top to bottom design method. This approach involves breaking down a system into smaller units to enable the designer get more insight into the system.

The major components of this system are as follows.

- Input Light Sensors (CdS).

- Analog to digital converter.

- Microcontroller.

- Tracking software.

- $\quad$ Output mechanical transducer (Servo Motor).

\subsection{Power Module}

This module powers the circuit. It consists of a $9 \mathrm{~V}$ battery. Other supportive components such as the voltage regulators are also contained therein. A battery was used because the microcontroller has to be online for optimum results to be achieved. Its active components are reviewed below. 


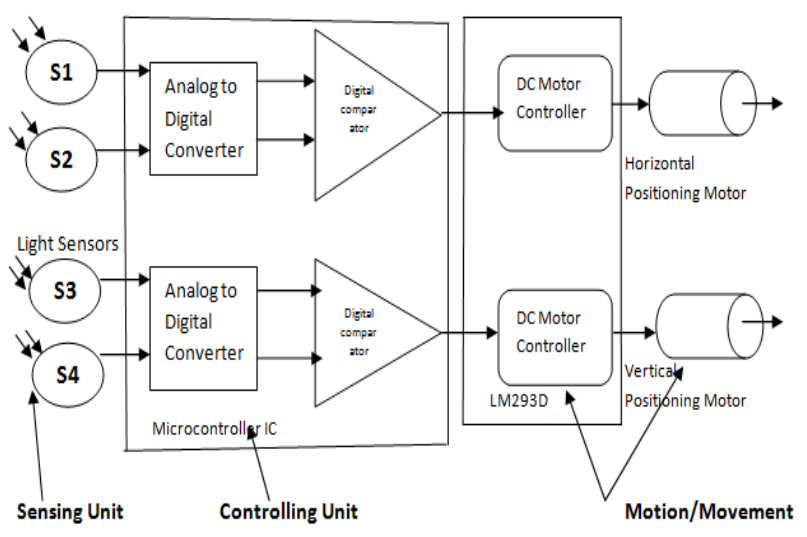

Figure 2: System Units

\subsection{Voltage Regulator (LM7805 and LM7806)}

Lm7805 and Lm7806 are used in this design.

Since there are two different powers supply being used; one for the circuit (5V) and another for the servo motor $(6 \mathrm{~V})$, the voltage regulator circuit is needed to regulate voltage $(9 \mathrm{~V}$ or $12 \mathrm{~V}$ ) from direct power supply. The main purpose of using two different power supplies is to supply the servo motor with the required voltage.

\subsection{Choice of Light Sensor (Cadmium Sulphide)}

A CdS photocell was chosen for the dual axis tracker. This is because it is the least expensive and least complex type of light sensor. The CdS photocell is a passive component whose resistance in inversely proportional to the amount of light intensity directed toward it. To utilize the photocell, it is placed in series with a resistor. A voltage divider is thus formed and the output at the junction is determined by the two resistances.

\subsection{Choice of Resistors}

Using just two series resistors and an input voltage, we can create an output voltage that is a fraction of the input. It was used to step down the voltage that is being fed in to the microcontroller. Four $10 \mathrm{~K} \Omega$ resistors were used for the design.

\subsection{Choice of Chip}

The ATMEGA 328P microcontroller was chosen because of the following features it possesses:

(i) It has the capacity to handle inputs from the user interface and the outputs to the servo motors.

(ii) It has the capacity to read four voltage levels simultaneously and continuously which is quite necessary in this application, since the output to the motor circuit requires four data channels to control movement of the servo motors.

In developing the software for the project, the following pins were used:

PIN 1: This is the reset pin, it is connected to a push button and a $10 \mathrm{~K}$ resistor, which is connected to $5 \mathrm{v}$ power supply, the duty of this resistor and push button is to reset the program, should the operator decide to restart the operation.

PIN 7: This is the power pin for the Microcontroller, a maximum of 5.5 volts and minimum of 4.5 volts can be sent to this pin to power the microcontroller.

PIN 8: This pin is connected to ground.

PIN 9 \& PIN10: A crystal oscillator is connected across pins 9 and 10, with a $22 \mathrm{pF}$ capacitor at each pin connected to ground. The purpose of the crystal oscillator and capacitor is to provide clocking for the microcontroller.
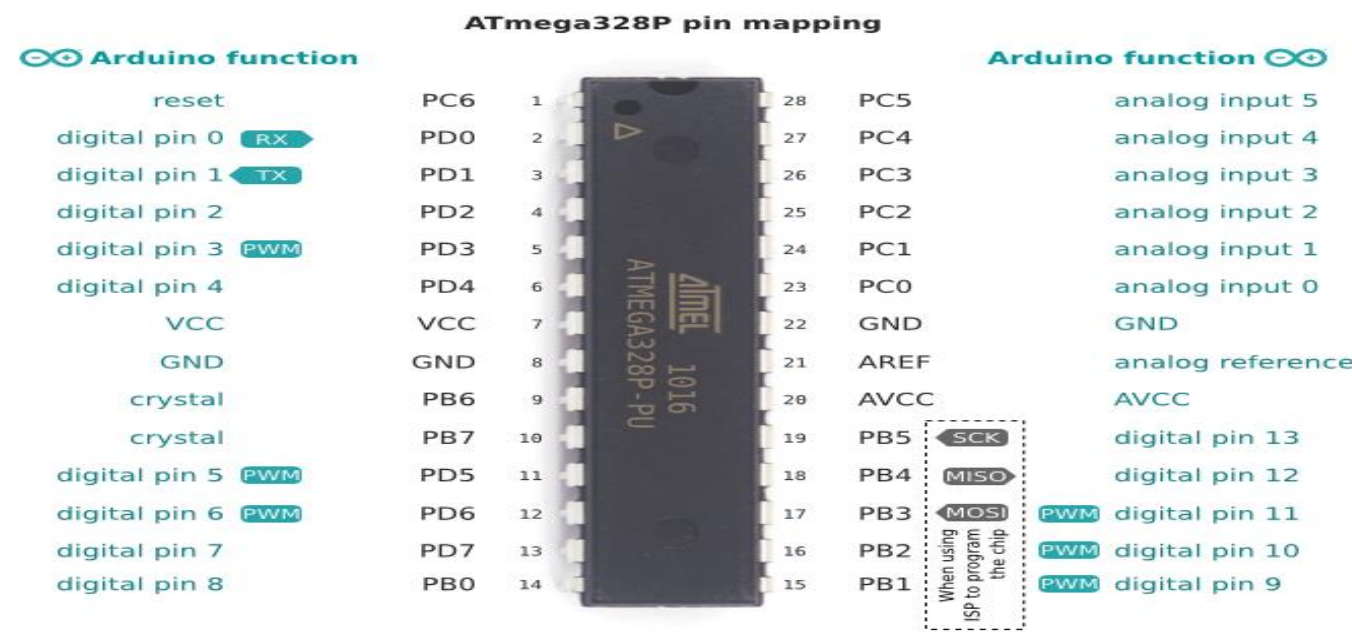

Fig 3: Pin Configuration of ATMEGA 328P PU 
PIN 15 \& PIN 16: This is a digital pin, in this project it has been programmed to act as the transmitting pin (TX), and receiving pin (RX). The pins have been programmed to communicate with the transmitting and receiving pin of servo motor $1 \& 2$.

PIN 20 \& 21: This pin is the reference voltage pin and ADC power pin; it serves as power source for the Analog-to-Digital converter.

PIN 22: This serves as the ground pin.

PIN 23, 24, 25 \& 26: This is the Analog pin, analog pin $0,1,2 \& 3$ this has been programmed to be an input pin, receiving values from the light dependent resistor sensor, produces values corresponding to voltages, it varies from 0 to 1023 .

PIN 28: This is an analog pin, analog pin 5, this is programmed as a receiving pin, and it is used to receive values from a voltage divider circuit.

\subsection{Choice of Controlling Motors [13]}

The microcontroller controls the servo motors by setting pins on the output ports that are connected to the motor input. These pins represent the Pulse Width Modulation (PWM) for the servo motors input to control the angle of their rotation.

The value of PWM that is fed into the servo motors is dependent on the input from the light sensor to control the angle of elevation and altitude of the sun or the light source. Selecting the best motor for your application depends on a few key design criteria for your system including cost, positional accuracy requirements, torque requirements, drive power availability, and acceleration requirements. For applications where high speed and high torque is needed, servo motors shine. Stepper motors peak around speeds of 2,000 RPM, while servo motors are available many times faster. Servo motors are also more efficient than stepper motors with efficiencies between $80-90 \%$. A servo motor can supply roughly twice their rated torque for short periods. At certain speeds, partially depending on the load dynamics, a stepper motor may enter resonance and be unable to drive the load. This results in skipped steps, stalled motors, excessive vibration and noise.

Servo motors are capable of delivering more power than stepper motors, but do require much more complex drive circuitry and positional feedback for accurate positioning. .

Overall, servo motors are best for high speed, high torque applications while stepper motors are better suited for lower acceleration, high holding torque applications.

\subsection{Specifications [13]}

- Weight: $55 \mathrm{~g}$

- Dimension: 40.7 x 19.7 x $42.9 \mathrm{~mm}$ approx.

- Stall torque: $9.4 \mathrm{kgf} \cdot \mathrm{cm}(4.8 \mathrm{~V}), 11 \mathrm{kgf} \cdot \mathrm{cm}(6 \mathrm{~V})$

- Operating speed: $0.17 \mathrm{~s} / 60^{\circ}(4.8 \mathrm{~V}), 0.14 \mathrm{~s} / 60^{\circ}$ (6 V)

- Operating voltage: $4.8 \mathrm{~V}$ a $7.2 \mathrm{~V}$

- Running Current $500 \mathrm{~mA}-900 \mathrm{~mA}(6 \mathrm{~V})$

- Stall Current 2.5 A (6V)

- Dead band width: $5 \mu \mathrm{s}$

- Stable and shock proof double ball bearing design

- Temperature range: $0 \stackrel{\circ}{\circ} \mathrm{C}-55^{\circ} \mathrm{C}$

\section{IMPLEMENTATION}

\subsection{Software implementation}

The program for the tracking controller has been written in C language code for the ATMEGA328P microcontroller. From the A/D the processor directly accesses the voltages and performs the necessary comparisons. After the comparisons are complete the processor uses a step algorithm to move the servo motors in the direction determined by the comparisons.

\subsubsection{Algorithm}

Microcontroller acts as brain of the whole solar tracking system. It will receive the desired light radiation through the CDS sensors. The input radiation to the sensors can then be compared to determine the position of the sun or the light source. The microcontroller then send the output signal to the servo motor for the desired angle of altitude and elevation angle.

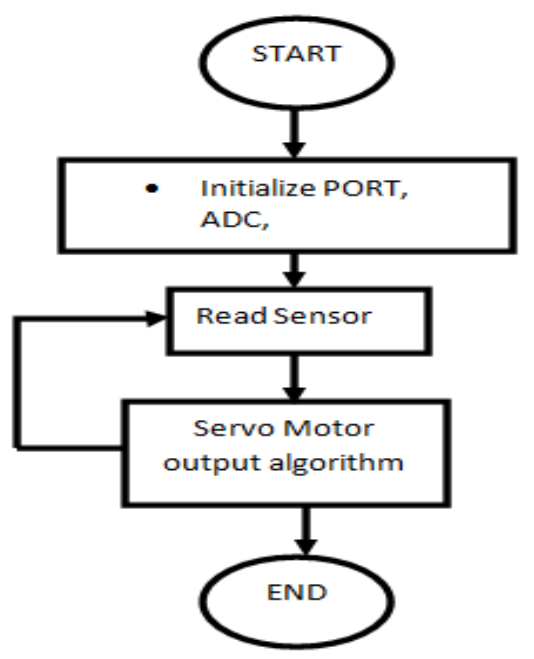

Figure 4: Flowchart 


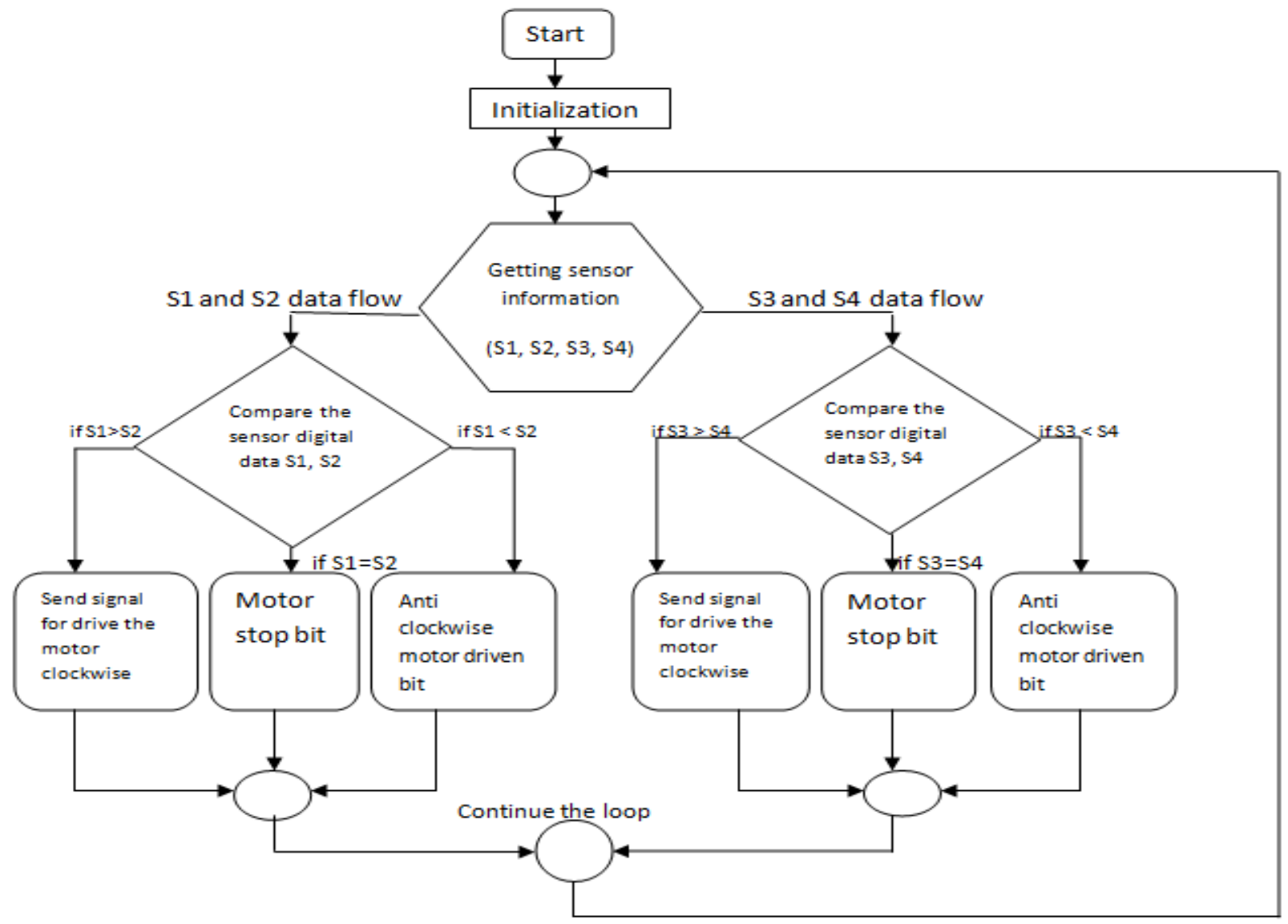

Fig 5: Servo Motor Algorithm

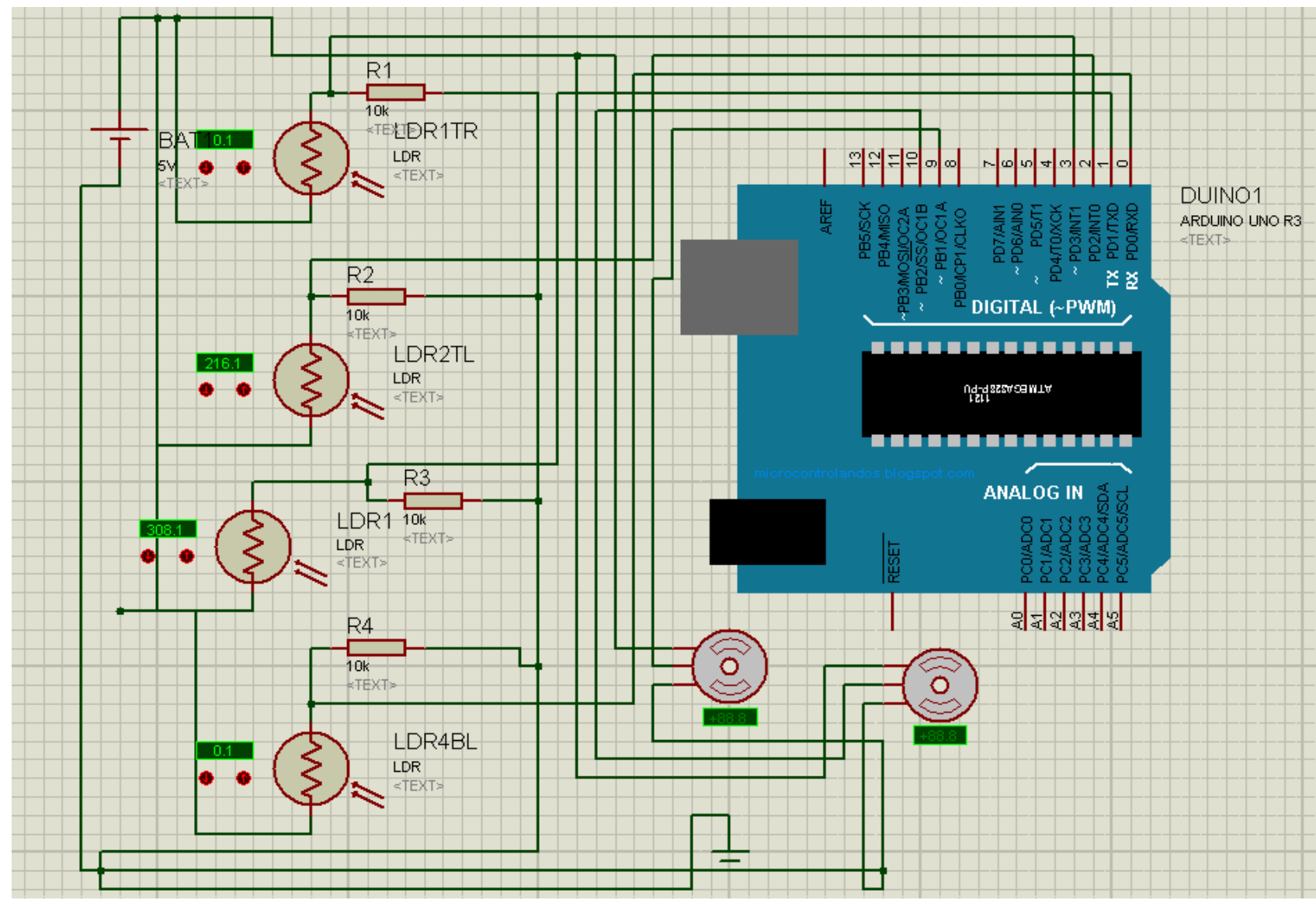

Figure 6: Software Simulation on Proteus 7 
An algorithm has to be developed to make the microcontroller to read the input and respond accordingly. Therefore, the algorithm is established and represented by a flowchart in Figure 4 and Figure 5 These flowcharts are then translated into $C$ language and compiled using the Arduino IDE. The program in C language can be referred in Appendix.

\subsection{Hardware Implementation}

After the design was done, it was simulated using Proteus 7 software as shown in Figure 2 and bread boarded. While the system was been designed, efforts were made to ensure that the components needed to implement the design were readily available and also affordable without compromising efficiency.

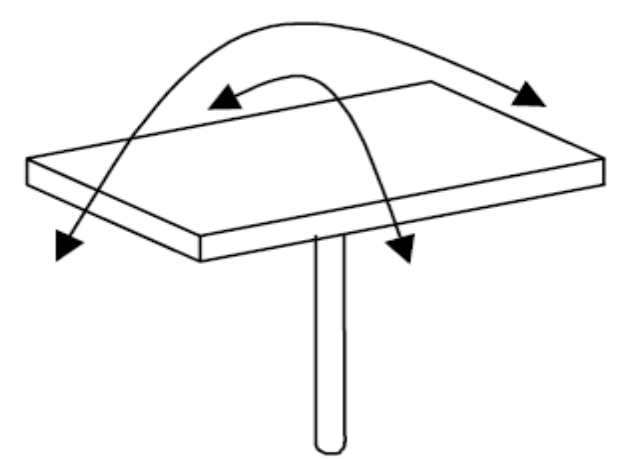

(a) Two axis tilt

\subsubsection{Method of Alignment}

Before the design of the sensing circuit can be considered, it is necessary to choose an appropriate method of alignment for the solar panel. The solar panel has a dimension of $13.5 \mathrm{~cm}$ by $11.4 \mathrm{~cm}$.

There are two ways of aligning the arrays viz;

(a) Two Axis Tilt: This involves tilting the array in two axes to maintain the required position as shown in Figure 7 (a).

(b) Rotate and Tilt: This involves rotating and tilting the array to maintain the same position as shown in Figure 7(b)

In this work, the two tilt method was adopted because it is flexible less complicated in terms of mechanical construction as stated earlier.

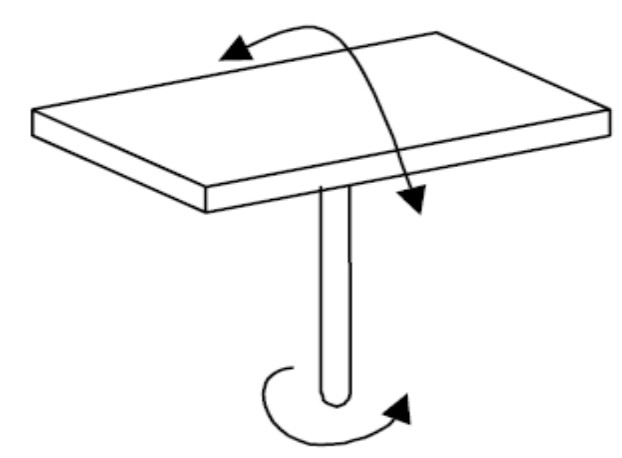

(b) rotate and tilt

Figure 7: Methods of Alignment of Solar Panel[5]

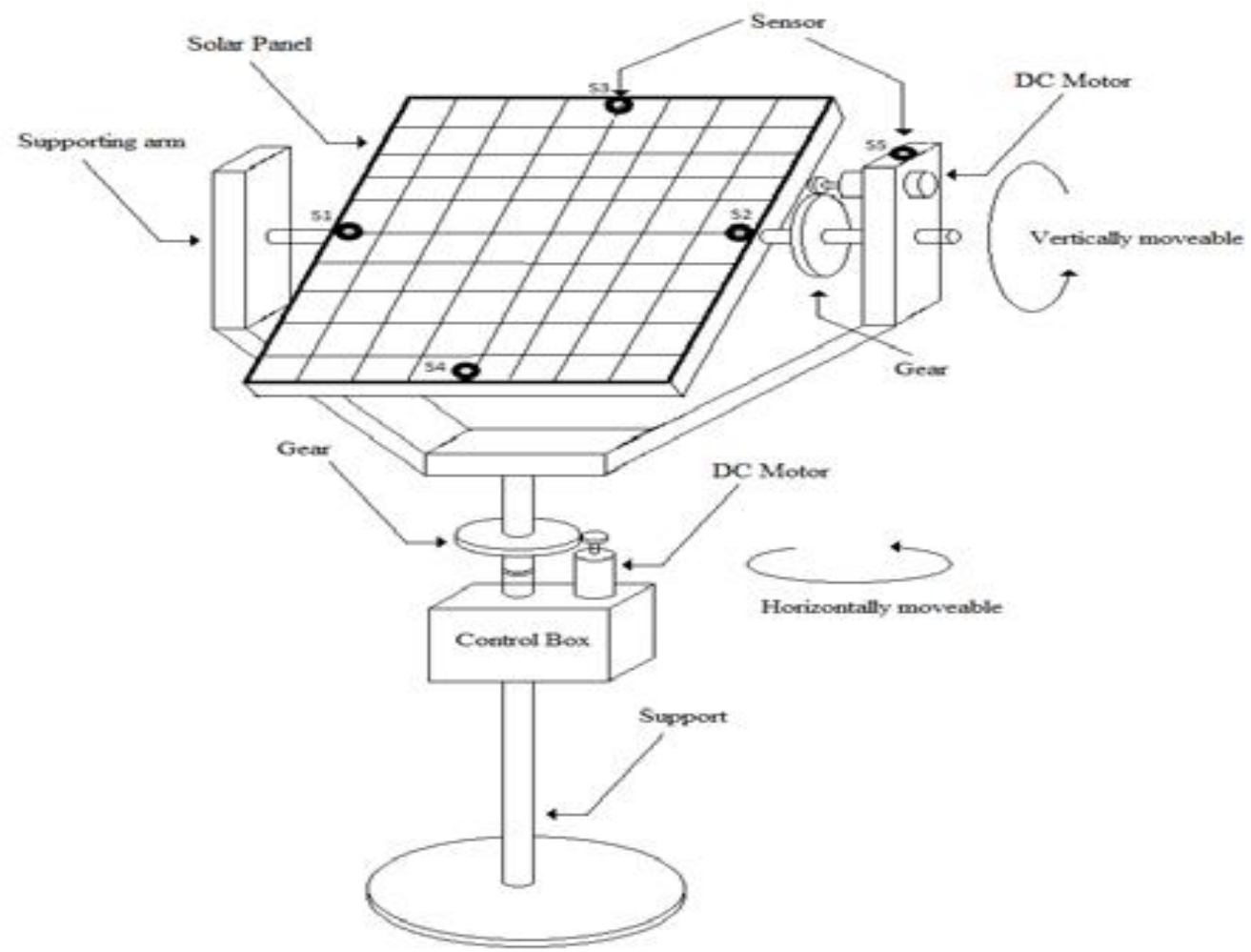

Figure 8: Gear System 


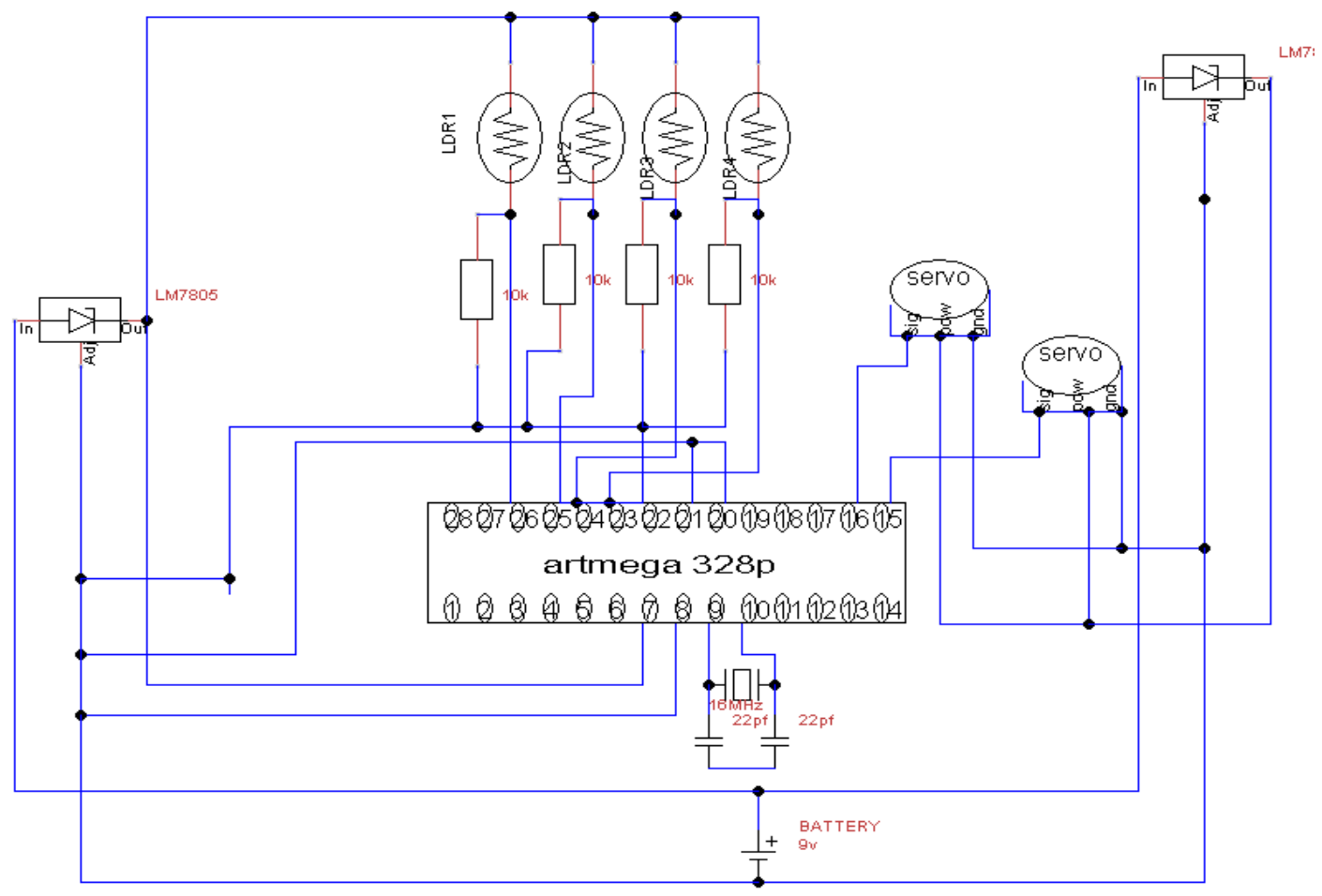

Figure 9: Complete Circuit Diagram

\subsubsection{Mode of Operation}

Figure 9 shows the complete circuit diagram of a microcontroller based dual axis solar radiation tracker. This system is used to tracker the radiation of the sun and face it directly such as it been 90 degrees the solar rays for high contact of the solar panel since energy converted by the solar panel is higher when it is directly 90 degrees to the sun radiation.

The system makes use of two voltage regulators but one battery source. When a DC voltage of $9 \mathrm{v}$ coming from the battery, the two regulators LM7805 and LM7806 produce $5 \mathrm{v}$ and $6 \mathrm{v}$ respectively wherein $5 \mathrm{v}$ goes to the light dependent resistors and also to the microcontroller. While $6 \mathrm{v}$ is fed directly to the servo motor

At night the LDR's detect no solar ray and are idle , but once solar radiation increases the four LDR's which work in pairs convert the solar radiation into analog signals and send them the microcontroller through pins 22, 23, 24 and 25 which do the comparisons..

The microcontroller does its comparison and sends signal to the servo motor through pin 15 and 16 to carry out adjustments, when necessary, so as to make the solar panel to face the direction with the highest intensity of solar radiation.

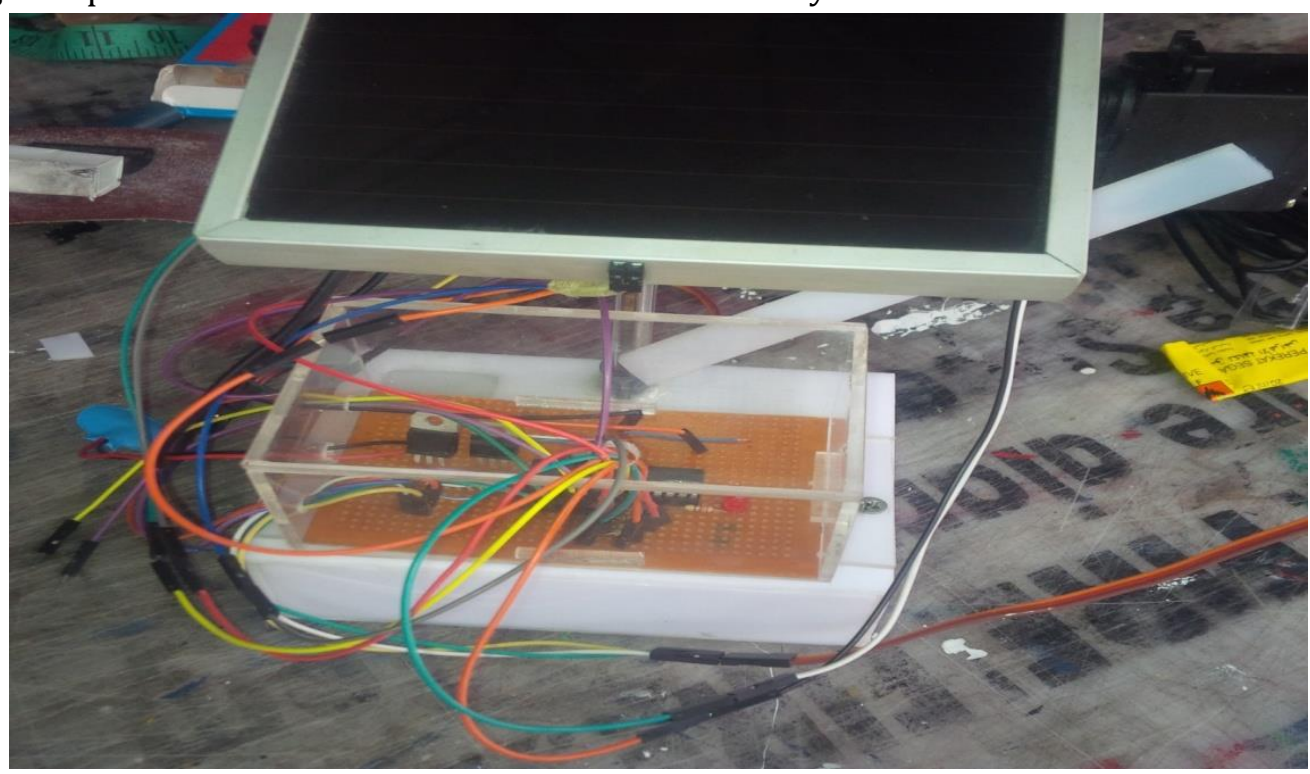

Figure 10 Pictorial View of the Microcontroller-Based Dual Axis Solar Tracker 
Table 2: Comparison between Stationary Panel and Tracking Solar Panel in Volts

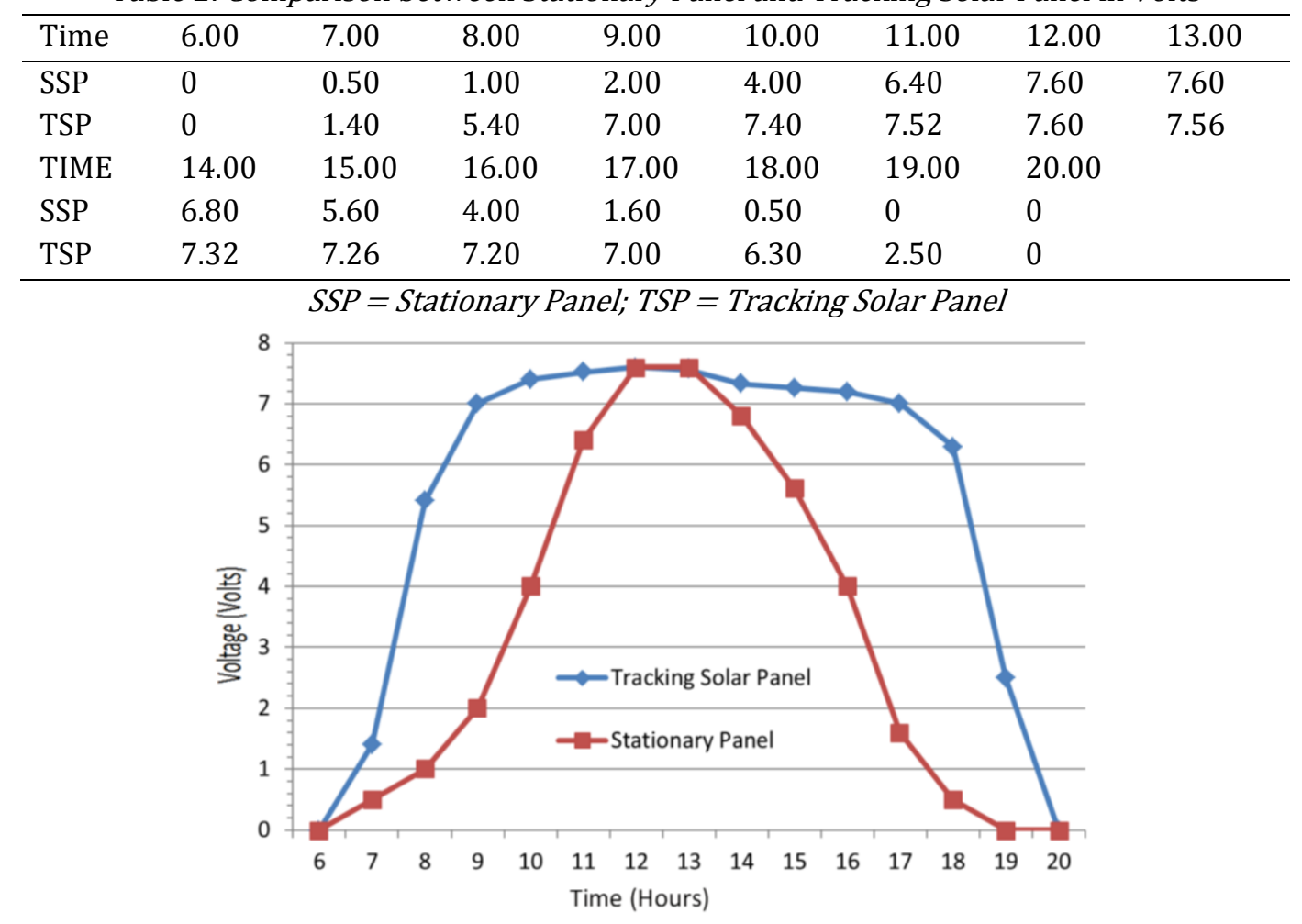

Figure 11.Plot of Output Voltage with Fixed Panel vs Dual Axis Control

\section{RESULTS/DISCUSSIONS}

This experiment involved a solar panel with four (4) solar cells which was mounted at the top of a platform where shade interfered. Table 2 represents the voltage values received from both the static and tracking solar panels at different times of the day, while Figure 11 shows the curve. From Table 2 it can be seen that there is much improvement in voltage level in the tracking solar panel system compared the static panel at $9.00 \mathrm{am} / 9.00 \mathrm{hrs}$. However, as the time goes on the difference decreases up to $12.00 \mathrm{pm} /$ $12.00 \mathrm{hrs}$. Thereafter, it increases as the sun rotates more towards the west.

\section{CONCLUSION}

This paper has presented a means of controlling a sun tracking array with an embedded microcontroller chip. Specifically, it demonstrates a working software solution for maximizing solar cell output by positioning a solar array at the point of maximum light intensity. It employed a microcontroller in its control circuitry as against others that employed programmable logic array. It uses dual axis tracking system, instead of single axis tracking system. Experimental results showed that the power output of the photovoltaic (PV) system had 58.4\% improvement when compared with the traditional method of fixed solar panel. Also, this system also offers significant reduction in cost as the number of solar panels to be deployed would be reduced due to the improvement in power output and efficiency.

Acknowledgements: The authors would like to acknowledge Mr. Akinrelere Oluwabusayo for his immense contributions.

\section{REFERENCES}

[1] Rinkesh, "Global Warming Causes," [Online]. Available: http://www.conserveenergyfuture.com/ globalwarmingcauses.php. [Accessed 0802 2016]

[2] M. B. Oumarou, A. A. Toyin and F. A. Oluwole, "Design Optimization and Performance Evaluation of a Single Axis Solar Tracker," Renewable and Sustainable Energy, vol. 3, no. 1, p. 9, 2015.

[3] Apricus.com, "African Solar Insolation Levels," [Online]. Available: http://www.apricus.com/ ipload/userfiles/insolation-levels-Africa.jpg. [Accessed 0205 2016].

[4] D. V. Schroeder, "The Sun and the Seasons," [Online]. Available: http://physics.weber.edu/schroeder/ ua/SunAndSeasons.html. [Accessed 0205 2016].

[5] Y. F. Mohamad, Design and Development of a Solar Tracking System, University of Technology, Malaysia: 2010, B.Eng Thesis (Unpublished). 
[6] S. Rahman, R. Ferdaus, M. Mannan and M. Mohammed, "Design and Implementation of a Dual Solar Tracking System," American Academic and Scholarly Research Journal, vol. 5, no. 1, p. 47, 2013.

[7] Y. Udoakah and O. I.N, "Determination of Optimal Tilt Angle for Maximum Solar Insolation for PV Systems in Enugu-Southern Nigeria," Nigerian Journal of Technologyvol. 34, no. 4, p. 838, 2015.

[8] D. Nnadi, S. Oti and D. Ahiabuike, "Mechanical SunTracking Technique Implemented for Maximum Power-Point Tracking of a PV System for Effective Energy Supply," Nigerian Journal of Technology, vol. 33, no. 2, 2014.

[9] J. Figueeiredo and J. Costa, "Intelligent Sun-Tracking System for Efficiency Maximization of Photovoltaic Energy ProductionIn," in International Conference on Renewable Energies and Power Quality, Spain, 2008.

[10] electronicoscaldas.com, "Datasheet," [Online]. Available: http://www.electronicoscaldas.com/ datasheet/MG996R_tower-Pro.pdf. [Accessed 0205 2016].

[11] "Cytron Technologies Sdn Bhd," 15 august 2008. [Online]. Available: www.cytron.com.my. [Accessed November 2015].

[12] O. Gustavo, C. Anaya, D. Figueroa and N. Pitalua, "Solar Tracker of Two Degrees of Freedom for Photovoltaic Solar Cell Using Fuzzy Logic,"
Proceedings of the World Congress on Engineering, vol. II, 6-8 July 2011.

[13] "solar4panel," [Online]. Available: http://solar4power. com/ solar-power-globalmaps.html. [Accessed november 2015].

[14] "solardat," uoregon, [Online]. Available: http://solardat.uoregon.edu/

SolarPositionCalculator.html. [Accessed November 2015].

[15] "Intelligent Control Systems Laboratory," [Online]. Available: http://www.gu.edu.au/ text/centre/icsl/home.html. [Accessed november 2015].

[16] M. F. Khan and R. L. Ali, "Automatic sun tracking system," in All Pakistan Engineering Conference, Islamabad, Pakistan, 2005.

[17] S. Takemaro and S. Yukio, "Theoretical concentration of solar radiation by central receiver systems," Solar Energy, 31(3) 1983, pp. 261 - 270.

[8] A. Saxena and V. Dutta, "A versatile microprocessor based controller for solar tracking," in IEEE 21st Photovoltaic Specialists Conference, Kissimmee,FL, 1990.

[19] electronicoscaldas.com, "Datasheeet," [Online]. Available: http://www.electronicoscaldas.com/ datasheet/MG996R_Tower-Pro.pdf. [Accessed 0205 2016]. 